\title{
Transplantation of bone marrow mononuclear cells decreases seizure incidence, mitigates neuronal loss and modulates pro-inflammatory cytokine production in epileptic rats
}

\author{
Zaquer S.M. Costa-Ferro ${ }^{\text {a,b }}$, Bruno S.F. Souza ${ }^{\text {b,c }}$, Marcos M.T. Leal ${ }^{\text {b }}$, Carla Martins Kaneto ${ }^{\text {, }}$ \\ Carine Machado Azevedo b ${ }^{\text {, Igor Campos da Silva }}{ }^{\text {b,d }}$, Milena B.P. Soares ${ }^{\text {b,c }}$, \\ Ricardo Ribeiro-dos-Santos ${ }^{\mathrm{b}}$, Jaderson C. DaCosta ${ }^{\mathrm{a}, *}$ \\ a Instituto de Pesquisas Biomédicas e Instituto do Cérebro, Pontifícia Universidade Católica do Rio Grande do Sul, Porto Alegre, RS, Brazil \\ b Centro de Biotecnologia e Terapia Celular, Hospital São Rafael, Salvador, BA, Brazil \\ c Centro de Pesquisas Gonçalo Moniz, Fundação Oswaldo Cruz, Salvador, BA, Brazil \\ ' Serviço de Anatomia Patológica e Citopatologia, Hospital São Rafael, Salvador, BA, Brazil
}

\section{A R T I C L E I N F O}

\section{Article history:}

Received 10 May 2011

Revised 25 October 2011

Accepted 4 December 2011

Available online 11 December 2011

\section{Keywords:}

Temporal lobe epilepsy

Bone marrow mononuclear cells

Seizure frequency

Neuronal loss

Cytokines

Pilocarpine

\begin{abstract}
A B S T R A C T
Approximately $30 \%$ of patients with mesial temporal lobe epilepsy do not respond to treatment with antiepileptic drugs. We have previously shown that transplantation of mononuclear bone marrow cells (BMC) has an anticonvulsant effect in acute epilepsy. Here, we used pilocarpine to induce epilepsy in rats and studied the effects of BMC injected intravenously either at the onset of seizures or after 10 months of recurrent seizures. BMC effectively decreased seizure frequency and duration. In addition, decreased levels of proinflammatory cytokines (TNF- $\alpha$, IL-1 $\beta$ and IL-6) and increased levels of anti-inflammatory cytokine (IL-10) were observed in the brain and serum of BMC-treated rats. Transplants performed at seizure-onset protected against pilocarpine-induced neuronal loss and gliosis and stimulated the proliferation of new neurons in epileptic rats. Our data demonstrate that BMC transplantation has potent therapeutic effects and could be a potential therapy for clinically intractable epilepsies.
\end{abstract}

(C) 2012 Elsevier Inc. All rights reserved.

\section{Introduction}

Temporal lobe epilepsy (TLE) is the most common type of epilepsy in adults (Engel, 1996). Mesial temporal epilepsy is a subtype of TLE associated with hippocampal sclerosis (Engel, 2001a; Wieser, 2004) and is one of the most frequent types of drug-resistant epilepsy (Engel, 2001a, 2001b). Clinical and neuropathological findings support the hypothesis that TLE with hippocampal sclerosis develops in 3 phases: a postnatal initial precipitating injury, a latent period corresponding to epileptogenesis, and the occurrence of spontaneous recurrent seizures (SRS; Mathern et al., 1996). In rats, status epilepticus (SE) induced by the systemic injection of the muscarinic receptor agonist pilocarpine is followed by a seizure-free period (latent phase) prior to the onset of SRS (Turski et al., 1987). SRS is accompanied by hippocampal cell loss, axon sprouting (Mello et al., 1993), and increased neurogenesis

* Corresponding author at: Instituto do Cérebro, Pontifícia Universidade Católica do Rio Grande do Sul (PUCRS), Av. Ipiranga 6690, 90610-000, Porto Alegre, RS, Brazil. Fax: + 555133203312 .

E-mail address: samuelgreggio@yahoo.com (J.C. DaCosta)

Available online on ScienceDirect (www.sciencedirect.com).
(Parent et al., 1997). In recent years, reports have suggested that inflammatory processes in the brain contributes to epilepsy and seizure recurrence (Vezzani and Granata, 2005; Vezzani et al., 2008).

Due to its focal nature and associated tissue degeneration, TLE is an attractive target for cell therapy applications. The bone marrow mononuclear cell fraction (BMC) contains populations of mesenchymal and hematopoietic stem cells that secrete a host of cytokines and growth factors involved in natural repair processes (Takahashi et al., 2006). A contribution of BMC to the regeneration of brain injuries has been already demonstrated (Brazelton et al., 2000; Eglitis and Mezey, 1997). In a rodent brain ischemia model, BMC (Baker et al., 2007; Brenneman et al., 2010; de Vasconcelos dos Santos et al., 2010; Giraldi-Guimarães et al., 2009; Iihoshi et al., 2004; Kamiya et al., 2008) and/or mesenchymal stem cells (Bao et al., 2011; Chopp and Li, 2002; Hu et al., 2004; Liu et al., 2009; Zacharek et al., 2010) were highly effective in promoting functional neurological recovery. In the clinical trials of cell-based therapies already performed, the results were highly promising in stroke and spinal cord injury (see review by Walker et al., 2010). In epileptic models, we demonstrated that BMC transplantation immediately after SE prevents the chronic seizure development, reduces neuronal loss, and influences reorganization of the hippocampal neuronal network (Costa-Ferro et al., 2010). 
The objective of the present study was to evaluate the therapeutic potential of BMC in rats during the chronic phase of pilocarpineinduced epilepsy and its possible mechanisms of action.

\section{Materials and methods}

\section{Animals}

Male Wistar rats (50-60 days old) were used. Food and drinking water were available ad libitum. Enhanced green fluorescent protein (GFP)-transgenic adult male C57BL/6 mice were used as BMC donors. All animal procedures were approved by the Animal Care and Ethics Committee of Pontifícia Universidade Católica do Rio Grande do Sul, RS, Brazil. All experiments were conducted in a blinded manner relative to the treatment condition of the animals. Every effort was made to minimize the animal's suffering and to reduce the number of animals used. The "Principles of laboratory animal care" (NIH publication No. 85-23, reviewed 1996) were strictly followed.

\section{Induction of SE and epilepsy}

All rats received intraperitoneal (i.p.) injections of lithium chloride $(127 \mathrm{mg} / \mathrm{kg}$, Sigma, St. Louis, MO, USA) and methylscopolaminebromide ( $1 \mathrm{mg} / \mathrm{kg}$, Sigma) $18-20 \mathrm{~h}$ and $30 \mathrm{~min}$, respectively, prior to induction of SE. SE was induced by treatment with pilocarpine ( $50 \mathrm{mg} / \mathrm{kg}$, i.p. Sigma) and was interrupted after $2 \mathrm{~h}$ by administering the anticonvulsant diazepam ( $20 \mathrm{mg} / \mathrm{kg}$ i.p.). Control animals were given saline (i.p.) (adapted from Clifford et al., 1987). The severity of seizures was rated using the Racine scale (Racine, 1972), and only those animals that displayed class $\mathrm{V}$ behavioral seizures were used in the study.

\section{BMC and fibroblast preparation and transplantation}

BMCs were harvested from male EGFP-transgenic mice. The animals were euthanized with $200 \mu \mathrm{l}$ of $8 \%$ ketamine hydrochloride (Cristália, Brazil) and 2\% chlorpromazine (União Química, Brazil) prior to dissection. Fresh bone marrow was extracted from the humerus, femur, and tibia by flushing with PBS. After centrifugation, the cell pellet was resuspended with RPMI medium and fractionated on a density gradient generated by centrifugation over a Ficoll-Hypaque solution (Histopaque 1119 and 1077, 1:1; Sigma) at $400 \times g$ for $30 \mathrm{~min}$ at room temperature. The mononuclear fraction over the Ficoll-Hypaque layer was collected and washed twice with PBS. After washing by centrifugation at $300 \times g$ for $10 \mathrm{~min}$, the viable cells with trypan blue were counted in a Neubauer chamber.

We used fibroblasts from the L929 cell line as a control for BMC transplantation. Fibroblasts were maintained in DMEM with $10 \%$ FBS and $50 \mathrm{~g} / \mathrm{ml}$ gentamicin (Sigma) in culture flasks incubated at $37{ }^{\circ} \mathrm{C}$ in $5 \% \mathrm{CO}_{2}$. After reaching $80-90 \%$ confluence, cells were treated with $0.05 \%$ trypsin solution (Sigma), washed in saline solution, resuspended in $1 \mathrm{ml}$ of saline and counted in a hemacytometer.

BMC and L929 cell suspensions were adjusted to a concentration of $1 \times 10^{7}$ cells $/ \mathrm{ml}$ in a volume of $100 \mu \mathrm{l}$. Cell suspensions or saline solution were administered by tail vein injection either 22 days or 10 months after SE.

\section{Flow cytometric analysis}

Mononuclear cells were washed with PBS and incubated at $4{ }^{\circ} \mathrm{C}$ for 30 min with conjugated antibodies against murine CD34 PE, CD90 PE, CD11b PE, CD44 PE, CD117 Cy5, CD45 APC and Sca-1 Cy5 (BD Pharmingen, San Diego, CA, USA). Labeled cells were analyzed using a FACScalibur cytometer (Becton Dickinson, San Diego, CA, USA) equipped with CellQuest software. At least 50,000 data points were collected. The means $\pm S D$ for the markers expressed by mononuclear cells were CD34 (4.86 \pm 0.43$),$ CD45 $(96.36 \pm 1.80)$, CD117 (13.95 \pm 0.88$), C D 11 b(60.22 \pm 3.30), C D 44(95.61 \pm 1.78)$, CD90 (8.10 \pm 1.28$)$, Sca1 $(36.06 \pm 1.8)$ and GFP $(96.52 \pm 0.76)$.

\section{Experimental groups}

Rats were video-recorded from the third day after SE to identify the onset of SRS. The seizures were quantified from day 15 to day 22 after SE, to determine pre-treatment seizure frequencies. On day 22 , the rats were randomly divided into three groups (Fig. 1): (A) epileptic rats transplanted 22 days after SE, which were further divided into the subgroups (1) epileptic (injected with saline solution), (2) mBMC (transplanted with mouse BMC) and (3) rBMC (transplanted with rat BMC); (B) epileptic rats transplanted with mBMC 10 months after SE, divided into the subgroups (1) epileptic (injected with saline solution) and (2) mBMC (transplanted with mouse BMC); and (C) L929 control cells, epileptic rats transplanted with L929 mouse fibroblasts. Each experiment also had a normal control group composed of non-epileptic rats that were injected with saline and were kept in the same housing conditions as the epileptic rats throughout the experiment.

\section{Monitoring of spontaneous recurrent seizures}

The frequency and duration of SRS were video-recorded for $8 \mathrm{~h}$ per day from 3 to 22 days post-SE. In all rats, the seizures were quantified between 15 and 22 days after SE. On day 22, randomly selected animals received $\mathrm{mBMC}$, rBMC or saline solution and were recorded for the first week following transplant.

Eight epileptic rats that presented a similar frequency of SRS at the first time point were transplanted with L929 cells and video-recorded during the first week immediately after transplantation and for one week per month in the three subsequent months.

In addition, ten non-treated epileptic rats, in which seizures were assessed from day 15 to day 22 after SE, were also video-recorded for one week in months 8,9 , and 10 after SE. Half of these animals received $\mathrm{mBMC}$ transplantation, and half received saline solution. Both $\mathrm{mBMC}$ and saline groups were video-recorded for SRS assessment in the following eight weeks.

For statistical analysis, we used the frequency and average duration of individual SRS 1 week pre- and post-treatment. Cumulative pre- and post-transplantation seizure scores were then compared to determine the percentage difference.

Histological evaluation and analyses of neurogenesis and migration of transplanted cells

Epileptic rats transplanted with mBMC or saline and non-epileptic rats of groups A and B were anesthetized with thiopental $(40 \mathrm{mg} / \mathrm{kg}$ i.p) and decapitated. Whole brains were removed and hemisected. One hemisphere was used for mRNA analysis, and the other was fixed in $4 \%$ paraformaldehyde for $24 \mathrm{~h}$. After fixation, the brains were dehydrated and embedded in paraffin. Serial coronal sections of $5 \mu \mathrm{m}$ were cut. Regions of interest were determined with the help of the rat brain atlas according to Franklin and Paxinos (1997), and points between the coordinates of the bregma $(-1.58-3.64 \mathrm{~mm})$ were analyzed.

Quantification of $\mathrm{NeuN}^{+}$cells

Neuronal counting was performed in coronal sections at approximately equidistant intervals localized between: -1.58 and $3.64 \mathrm{~mm}$ caudal from the bregma (Franklin and Paxinos, 1997). Nine sections were obtained from each animal per each region and time point. In each section, undamaged neurons of the hippocampal CA1, CA3 fields and hilus of DG were defined as follows (Fig. 4A). Hilus was defined as the inner border of the granule cell layer and the proximal end of the 

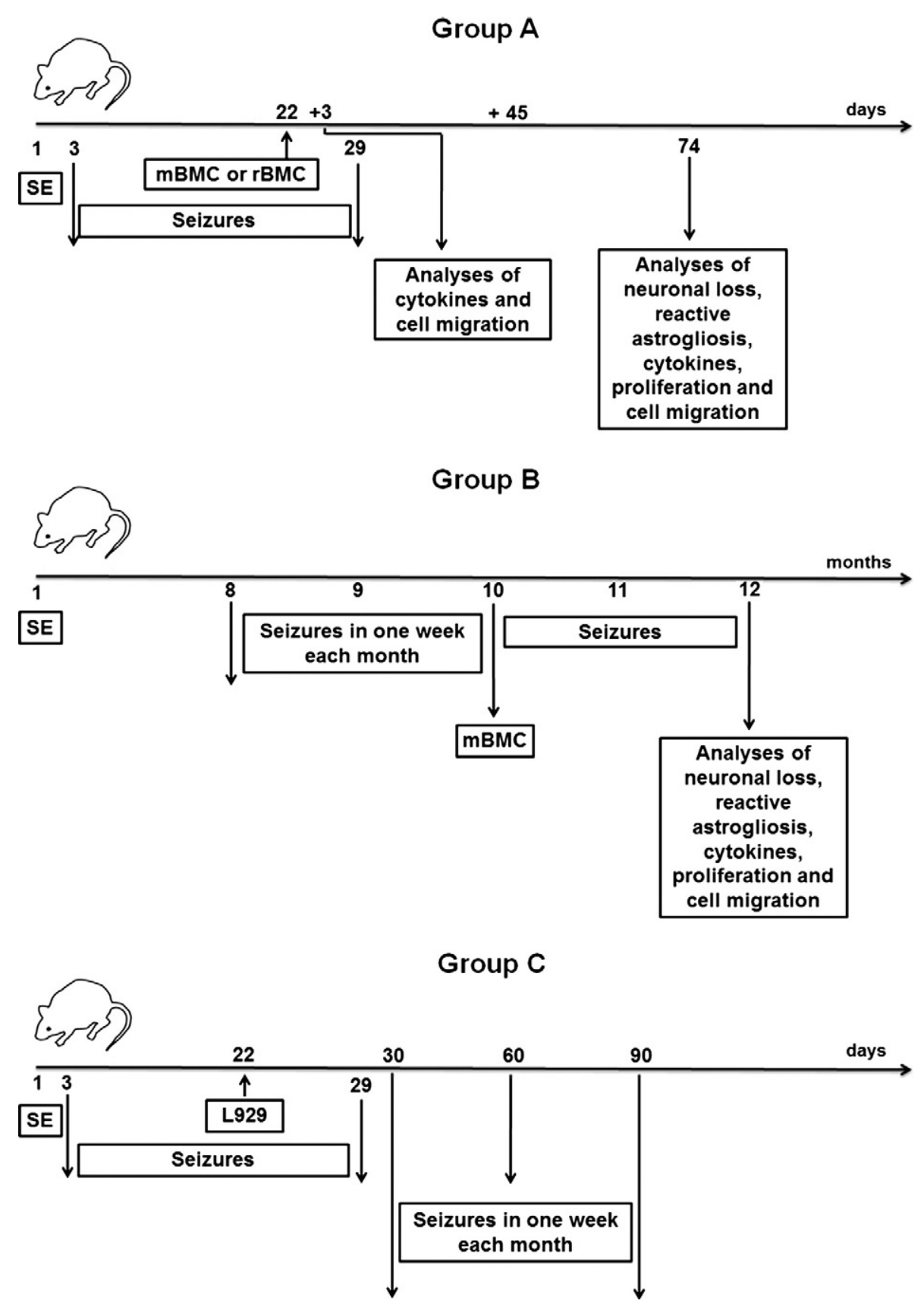

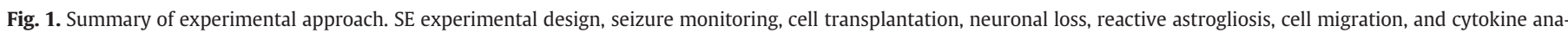

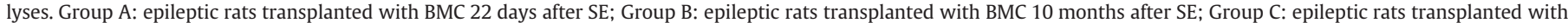
L929 fibroblasts.

CA3c/CA4 region. The images were obtained with a $40 \times$ lens, and neurons were counted within a frame with an area of $900 \mu \mathrm{m}^{2}$, using Image-Pro Plus analysis software v.7.0 (Media Cybernetics, Inc. USA). Neurons with visible DAPI-stained nuclei found overlaying the left and upper borders of the counting frame were counted together with the nuclei located within the analyzed square. The cell counts were corrected by Abercrombie's formula (Abercrombie, 1946).

\section{Nissl and hematoxylin-eosin staining}

Histological analysis of cells was performed in adjacent hippocampal sections stained by the Nissl method ( $1 \%$ cresyl violet) and hematoxylin-eosin (H\&E) $(-1.70,-2.46$ and $3.40 \mathrm{~mm}$ from bregma). The slides were scanned with an Aperio Scanscope (Aperio Technologies, San Diego, USA) under 20 or $40 \times$ magnification. Neuronal loss, reactive gliosis, edema, and microvascular proliferation (if present) were graded as mild, moderate, or severe.

\section{Quantification of $\mathrm{GFAP}^{+}$cells}

Sections containing GFAP-labeled glial cells were examined using zstacks obtained with a confocal microscope eighteen images per region $(-1.70,-2.46$ and $-3.40 \mathrm{~mm}$ from the bregma) were examined for each time point. Images of the stratum radiata of CA1 and CA3 as well as the hilus were digitally captured and analyzed using Image Pro Plus v. 7.0 (Media Cybernetics), which automates the analysis by segmentation, converting all immunolabeled elements that fall within a threshold range into red pixels and the rest of the image into yellow pixels. The same threshold range that defined positivity was used in all images analyzed. The software then calculates the percentage of red and 
yellow, allowing for the comparison of the pixel values between the groups, defined as the percentage of stained area.

\section{Doublecortin (DCX) staining}

The expression of the immature neuronal marker DCX (see below) was also analyzed (see antibodies section). Fluorescence signals from double-labeled sections were detected by confocal microscopy. For the CA1 and CA3, a single square with an area of $104.400 \mu \mathrm{m}^{2}$ was analyzed, and for the DG, 4 squares were analyzed. Mean values per each area per slice and per rat were used in the statistical analysis.

\section{GFP staining}

To investigate the migration of BMC to the brain in the group $\mathrm{A}$, $\mathrm{GFP}^{+}$cells were visualized by confocal microscopy 3 days after transplantation. GFP expression was also evaluated by real time quantitative polymerase chain reaction in groups A and B 45 and 60 days after transplantation, respectively (see below).

\section{Antibodies}

The slices were deparaffinized and rehydrated. Antigen retrieval was performed using citrate buffer $\left(\mathrm{pH}=6.0\right.$, at $\left.95-98^{\circ} \mathrm{C}\right)$ for $20 \mathrm{~min}$. The sections were incubated overnight at $4{ }^{\circ} \mathrm{C}$ with one of the following primary antibodies: biotinylated anti-neuronal nuclei antibody (NeuN, 1:100, Chemicon International, Temecula, CA, USA), rabbit anti-doublecortin (DCX, 1:800, Abcam, San Francisco, CA, USA), rabbit anti-glial fibrillary acidic protein (GFAP, 1:200, Neomarkers, CA, USA) or chicken anti-green fluorescence protein (GFP, 1:400, Avés
Lab, Tigard, OR, USA). The next day, sections were incubated for $1 \mathrm{~h}$ at room temperature with streptavidin or secondary antibodies (Streptavidin-Alexa Fluor 488 conjugated, anti-rabbit IgG Alexa Fluor 488, anti-rabbit IgG Alexa Fluor 633, 1:200, Molecular Probes, Carlsbad, CA, USA). Sections were washed twice in PBS Tween $0.05 \%$ and then in PBS, dried and coverslipped using Vectashield mounting medium with 40,6-diamidino-2-phenylindole (DAPI; Vector Laboratories, CA, USA) or TO-PRO (1:200, Molecular Probes). Images were taken using the Fluoview 1000 confocal microscope with the F10-ASW v.2.1 software (Olympus).

\section{Analysis of cytokine production}

The transcription of cytokine genes was evaluated by real-time quantitative polymerase chain reaction (qPCR) in rats sacrificed 3 and 45 days after transplantation (group A) and 60 days after transplantation (group B). Total RNA was isolated from the whole brain with TRIzol reagent (Invitrogen), and the concentration was determined by photometric measurement. High Capacity cDNA Reverse Transcription Kit (Applied Biosystems) was used to synthesize cDNA from $1 \mu \mathrm{g}$ of RNA following the manufacturer's recommendations. qRT-PCR assays were performed to detect the expression levels of TNF- $\alpha$ (tumor necrosis factor alpha), IL-1 $\beta$ (Interleukin 1 beta), IL-6 (Interleukin 6) and $I L-10$ (Interleukin 10) genes. Amplification mixtures for qRT-PCR contained $20 \mathrm{ng}$ template cDNA, $10 \mu \mathrm{l}$ Taqman Master Mix (Applied Biosystems) and probes and for TNF- $\alpha$ (Mm00443258_m1), IL-1ß (Mm00434228_m1) IL-6 (Mm00446190_ $\mathrm{m} 1)$ and $\mathrm{IL}-10$ (Mm00439616_m1) in a final volume of $20 \mu \mathrm{l}$. To detect transplanted mouse BMCs, GFP expression was also evaluated. All reactions were run in duplicate on an ABI7500 Sequence Detection
A

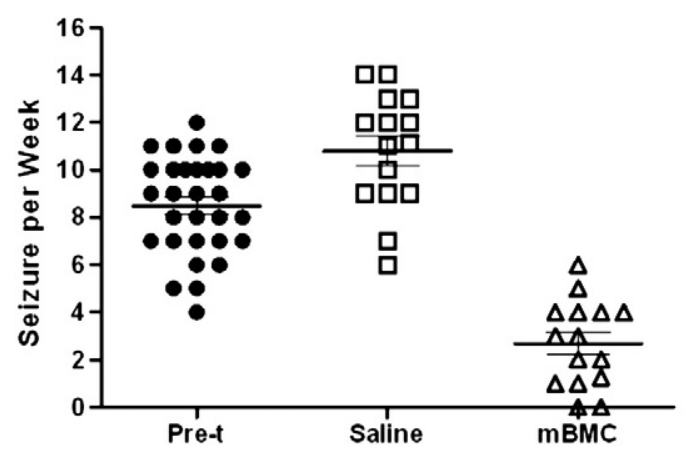

C

Group B - mBMC

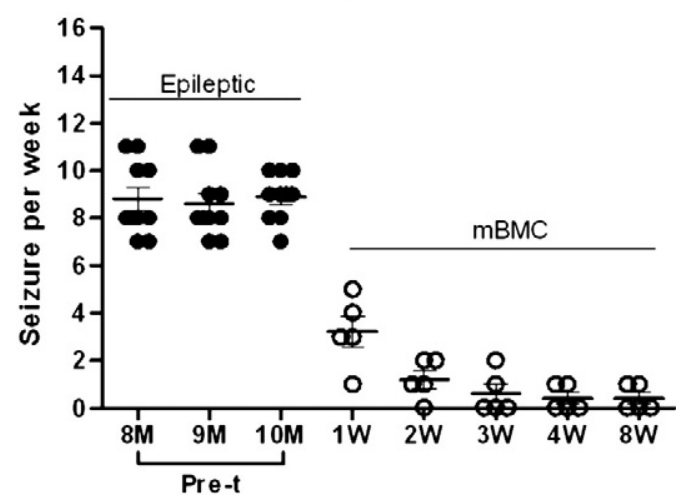

B

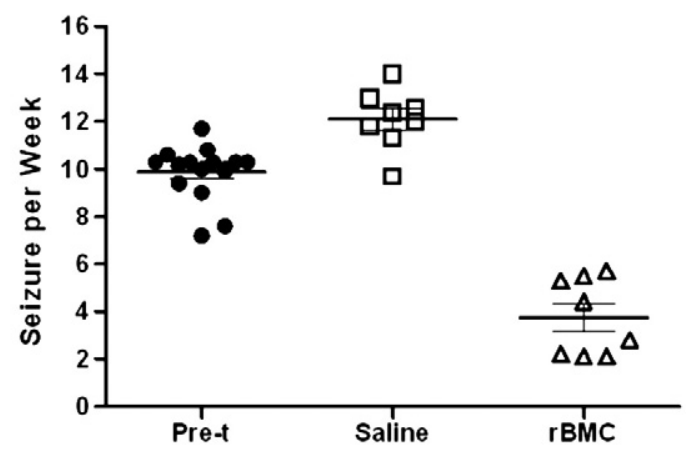

D

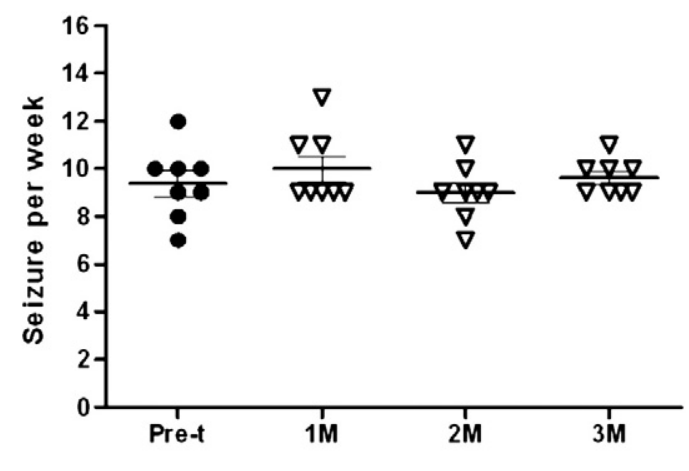

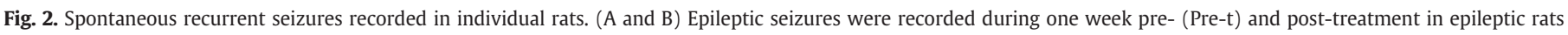

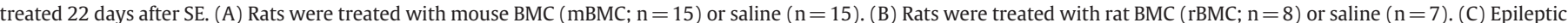

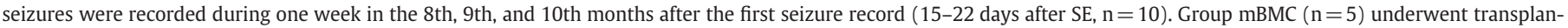

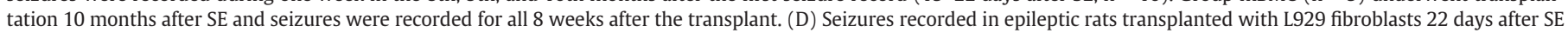
and recorded one week in each of the subsequent 3 months $(n=8)$. 
System (Applied Biosystems, Foster City, CA, USA) under standard thermal cycling conditions. Experiments with coefficients of variation greater than $5 \%$ were excluded. A no-template control (NTC) and no-reverse transcription controls (No-RT) were also included. The results are presented as the fold-increase of expression of the individual mRNAs, with the target internal control GADPH using the cycle threshold method.

Serum concentrations of IL-1 $\beta$, IL-6, IL-10, and TNF- $\alpha$ were determined by an enzyme-linked immunosorbent assay (ELISA) in group A and $B$ rats (the same animals included in the brain cytokine qPCR analysis). All cytokines were measured in duplicate using specific antibody kits (R\&D Systems, Minneapolis, MN, USA) according to manufacturer's instructions.

\section{Data analysis}

Statistical analyses were performed using Prism software (version 5.01, GraphPad Software, San Diego, CA, USA). Seizure frequency, neuronal loss, gliosis quantification and ELISA assays were analyzed with one-way analysis of variance (ANOVA) followed by Tukey's posttests or the Newman-Keuls multiple comparison test. $\mathrm{GFP}^{+}$cells and expression of mRNA was analyzed with two-way ANOVA followed by Bonferroni posttests or one-way analysis by Neuman-Keuls multiple comparison test. Differences in numbers of DCX-positive cells were analyzed with Student's t-tests. The data are presented as the mean \pm SD or mean \pm S.E.M., as indicated in the figure legends. Differences were considered significant if $p<0.05$.

\section{Results}

Pilocarpine-induced spontaneous seizures and the effects of BMC

Systemic administration of lithium and pilocarpine rapidly induced a robust convulsive SE (latency: $28 \pm 13 \mathrm{~min}$ ). The rats that did not develop SE were excluded from the study. The mortality rate in the seven days after pilocarpine treatment was approximately
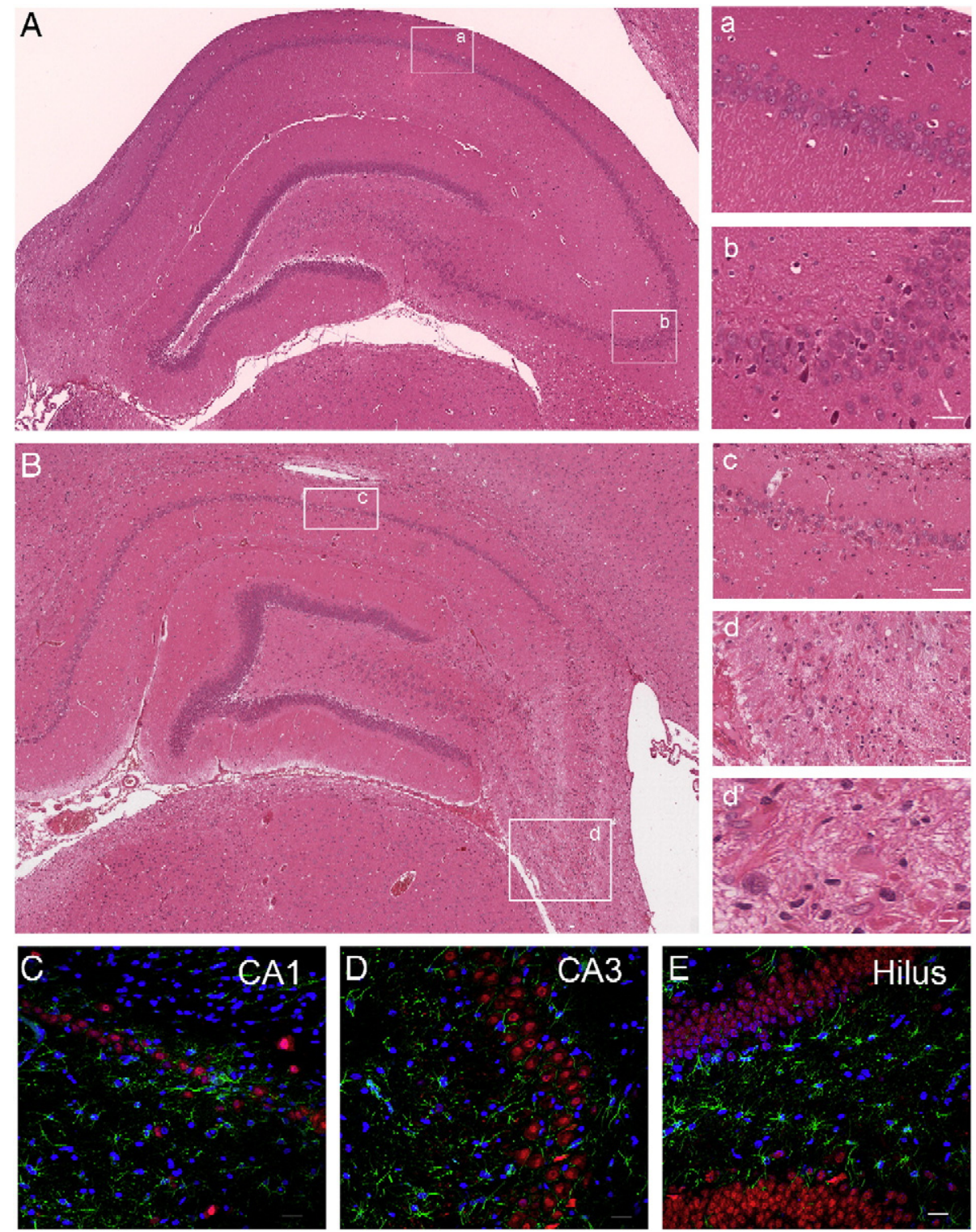

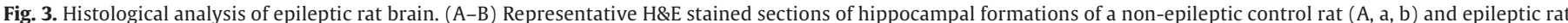

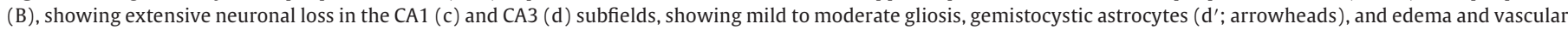

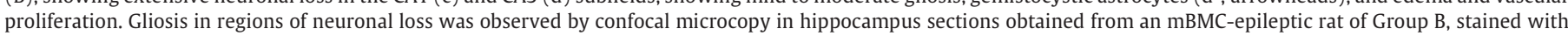
anti-GFAP (green), anti-NeuN (red) antibodies, and DAPI for nuclear visualization (C-E). Scale bars: $50 \mu \mathrm{m}$. 
$50 \%$, but significant mortality was not observed after the first week. SRSs began $12 \pm 5$ days following SE.

In group $\mathrm{A}$, which received transplants 22 days after $\mathrm{SE}$, the epileptic rats that received an injection of saline solution exhibited approximately $27 \%$ increase in the number of seizures/week. Conversely, in rats transplanted with BMCs, the number of seizures/week decreased by $65 \%$ in $\mathrm{mBMC}$ (Fig. $2 \mathrm{~A} ; p<0.001$; pre vs. $\mathrm{mBMC}$ transplantation) and $62 \%$ in rBMC (Fig. $2 \mathrm{~B} ; p<0.001$ pre vs. rBMCtransplantation).
For comparison, in group B, the occurrence of seizures was evaluated during the first week in months 8,9 and 10 after the first recorded seizure and for 8 weeks following transplantation. A significant difference in the frequency of SRS was observed between the groups. Epileptic animals exhibiting a similar frequency of SRS 8-12 months after SE showed a marked decrease in the number of SRS 1-4 weeks after transplantation. These low levels of SRS remained during the four subsequent weeks. There was a decrease of approximately $62 \%$ in the first week, $86 \%$ in the second, and $97 \%$ in the fourth

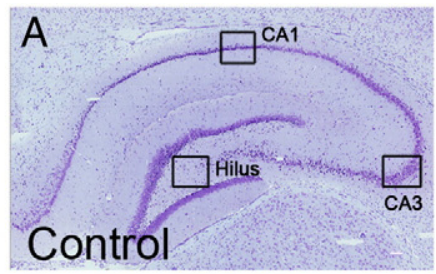

\section{Group A}
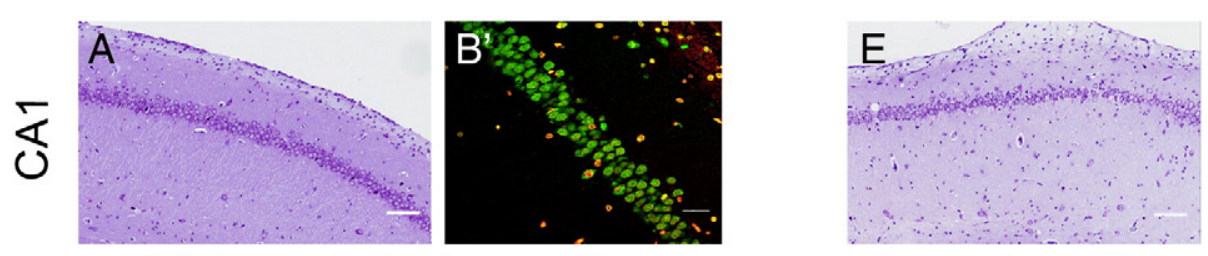

Saline
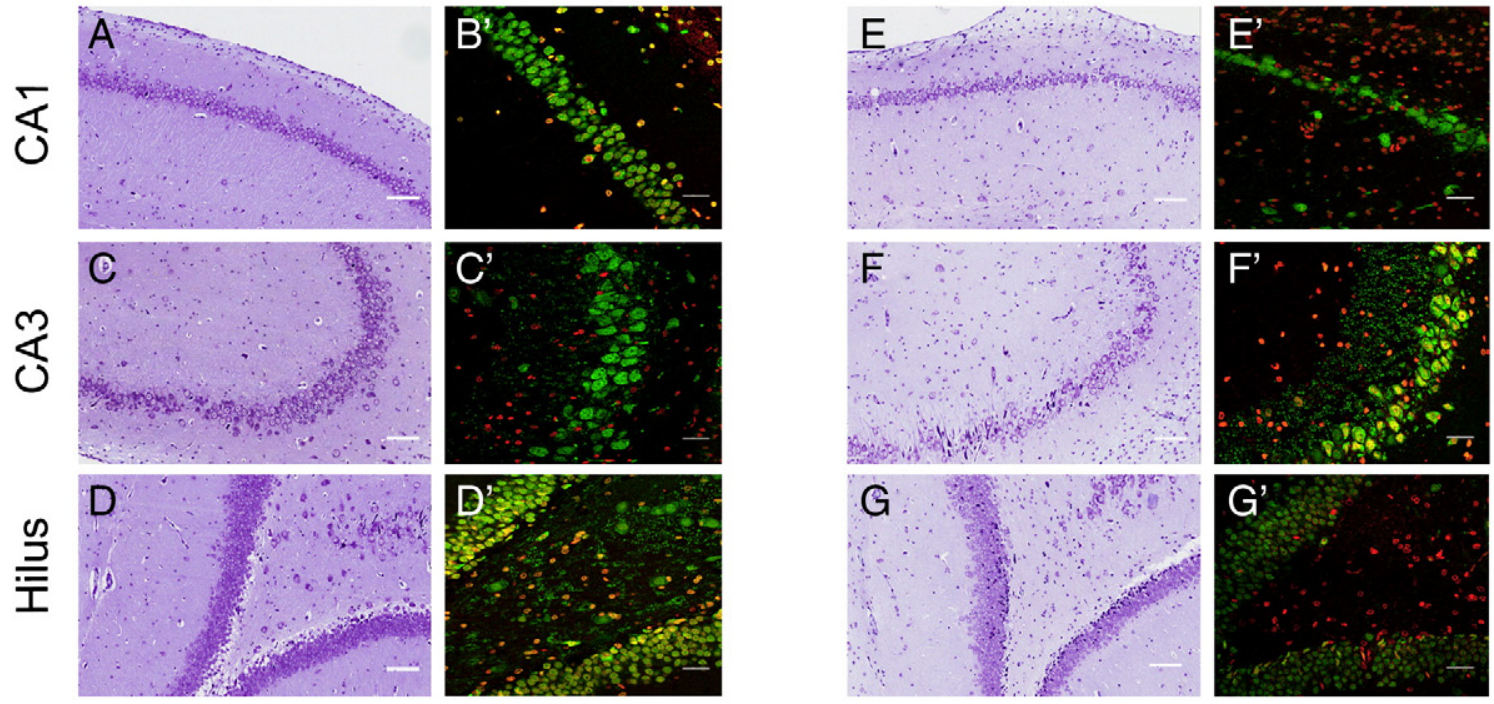

\section{Group B}
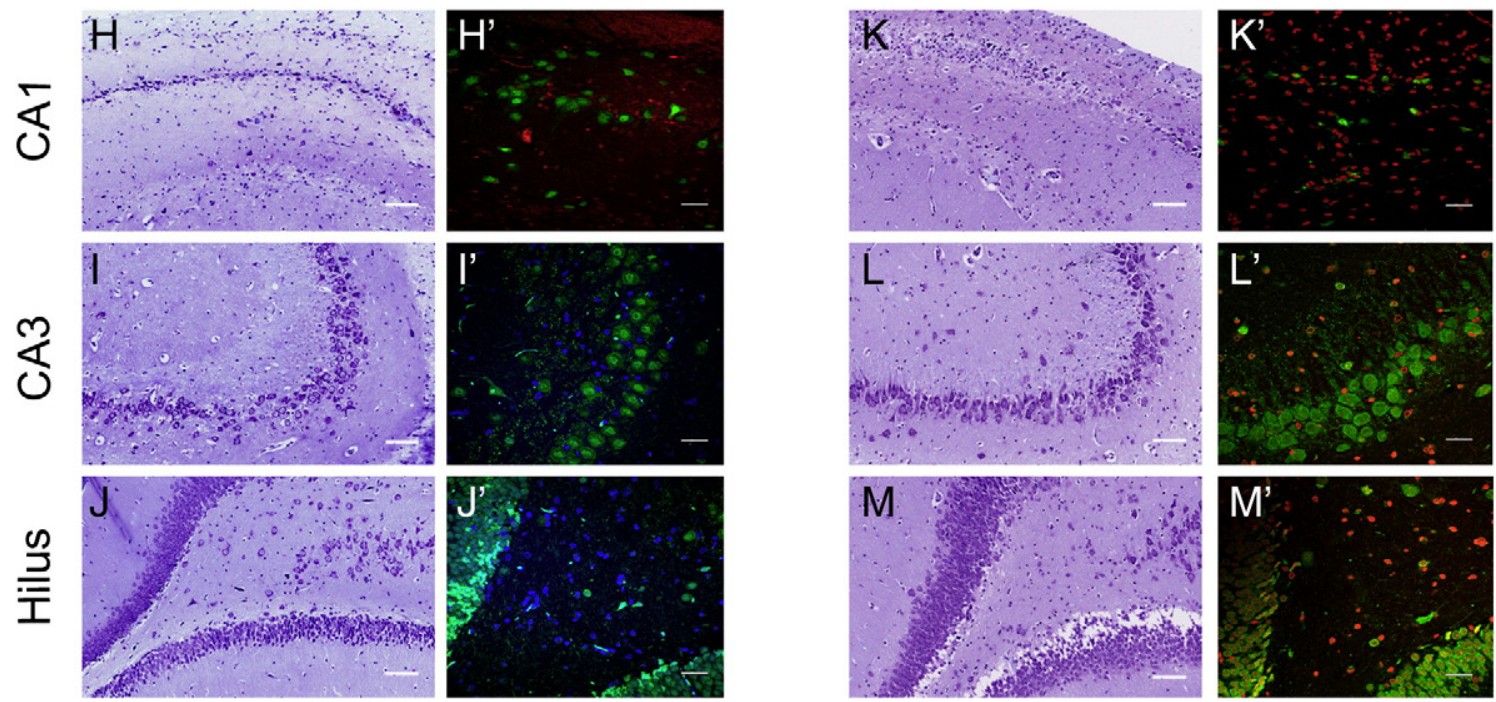

Fig. 4. Neuronal injury in the hippocampal formation. (A) Section from a control rat brain indicating the areas of analysis: CA1 and CA3 pyramidal cell layers and the hilus of DG. Group A: CA1, CA3 and hilar areas from mBMC-treated epileptic rats (B-D) and saline-treated epileptic rats (E-G). Group B: CA1, CA3 and hilar areas from mBMC-treated rats (H-J) and saline-treated epileptic rats $(\mathrm{K}-\mathrm{M})$. ( $\mathrm{A}-\mathrm{M})$ Nissl-stained sections. ( $\left.\mathrm{B}^{\prime}-\mathrm{M}^{\prime}\right)$ Confocal microscopy images of sections stained with anti-NeuN antibody (green) and DAPI (blue) or TO-PRO (red) for nuclei visualization. Scale bars: $50 \mu \mathrm{m}$, $(\mathrm{n}=5 / \mathrm{group})$. 
and eighth weeks after transplantation (Fig. 2C, $p<0.001$; salineepileptic vs. mBMC-epileptic rats for each time point).

A variable and significant difference was found in the mean duration of seizures: approximately $48 \%$ in the rBMC and mBMC-transplanted rats in the group $A$ and $57 \%$ in the $\mathrm{mBMC}$ in the group $\mathrm{B}(p<0.001)$.

In group $C$, rats transplanted with $L 929$ fibroblasts had no significant alteration in SRS frequency or duration during the entire observation period after transplantation compared to saline epileptic rats (Fig. 2D).

\section{Histological evaluation of the hippocampus}

Damage in the hippocampus was observed in both saline- and BMC-epileptic rats. In group A, two out of five animals from the saline-epileptic group showed evidence of active hippocampal inflammation, with few infiltrating leucocytes, moderate edema, vascular proliferation and reactive gliosis, with gemistocystic astrocytes, in areas of extensive neuronal loss. Most animals, however, presented variable degrees of neuronal loss and mild or moderate gliosis, with no edema or vascular proliferation in the evaluated areas. In group $\mathrm{B}$, we observed extensive neuronal loss together with mild-tomoderate gliosis, but no edema or vascular proliferation (Fig. 3).

Cresyl violet staining and NeuN immunofluorescence in the hippocampal regions was typically found in the pyramidal cell layers of CA1 and CA3 and the hilus of the dentate in epileptic rats (Figs. 4A-M). The number of $\mathrm{NeuN}^{+}$cells in these areas dramatically decreased in saline-epileptics rats (Figs. 5A-F, $p<0.001$ ), but BMCs significantly ameliorated cell loss in group A. Neuronal counts in the CA1 and CA3 regions of the $\mathrm{mBMC}$ group showed a small difference (Figs. $5 \mathrm{~A}$ and $\mathrm{C}, p<0.01$ ), but the number of neurons increased in the hilus (Fig. 5E, $p>0.05$ ) compared to control rats. In addition, the number of $\mathrm{NeuN}^{+}$cells in the CA1 and hilus of DG was preserved in the $\mathrm{mBMC}$ group compared with the saline-epileptic rats $(p<0.001$, Figs. $5 A$ and $E)$. In group B, we observed greater neuronal cell loss in the CA1 and hilus of DG in $\mathrm{mBMC}$ group (Figs. $5 \mathrm{~B}$ and $\mathrm{F}$; $p<0.001$ ), whereas in the CA3, only moderate damage was found (Fig. 5D; $p<0.01$ ).

In addition to changes observed in neuron populations, we found reactive astrogliosis as shown in Fig. 6. Astrocytes from control rats had small cell bodies and thin processes, while epileptic rat astrocytes had enlarged cell bodies and elongated processes. These characteristics were even more pronounced in epileptic rats from group B. We observed that these morphological changes were partially reversed in BMC-epileptic rats (Figs. 6A-L). We did not observe differences in the intensity of $\mathrm{GFAP}^{+}$area between saline-epileptic rats in groups $A$ and $B$, but we did observe differences in cell morphology. The quantification of GFAP-stained area in the same regions revealed increased GFAP expression in the epileptic rats compared to controls (Figs. 6M and $\mathrm{N} p<0.001$ ). In group $\mathrm{A}, \mathrm{BMC}$-epileptic rats had lower expression of GFAP when compared to saline-epileptic rats (Fig. 6M, $p<0.001$ ).

\section{Effects of BMC on hippocampal neurogenesis}

Seizures upregulate a number of factors that increase endogenous neurogenesis in the DG (Parent et al., 1997). We investigated whether prior seizure experience affected the fates of transplanted mBMC. DCX is a protein expressed in immature neurons and is associated with neuronal differentiation (Ming and Song, 2005). Therefore, staining for DCX, NeuN and DAPI was performed. In group A, DCX ${ }^{+}$ cells were present in the CA1 (Fig. 7A) and in the DG (Fig. 7B) of mBMC-epileptic rats 45 days after transplantation. They were also seen in the DG in saline-epileptic rats at the same time point (Fig. 7C). Moreover, the number of $\mathrm{DCX}^{+}$cells was increased in the salineepileptic group compared to the mBMC-epileptic group (Fig. 7D, $p<0.01$ ). The brains of rats transplanted with mBMC 10 months after $\mathrm{SE}$ were examined 60 days after transplantation (group B). Most of

\section{Group A}
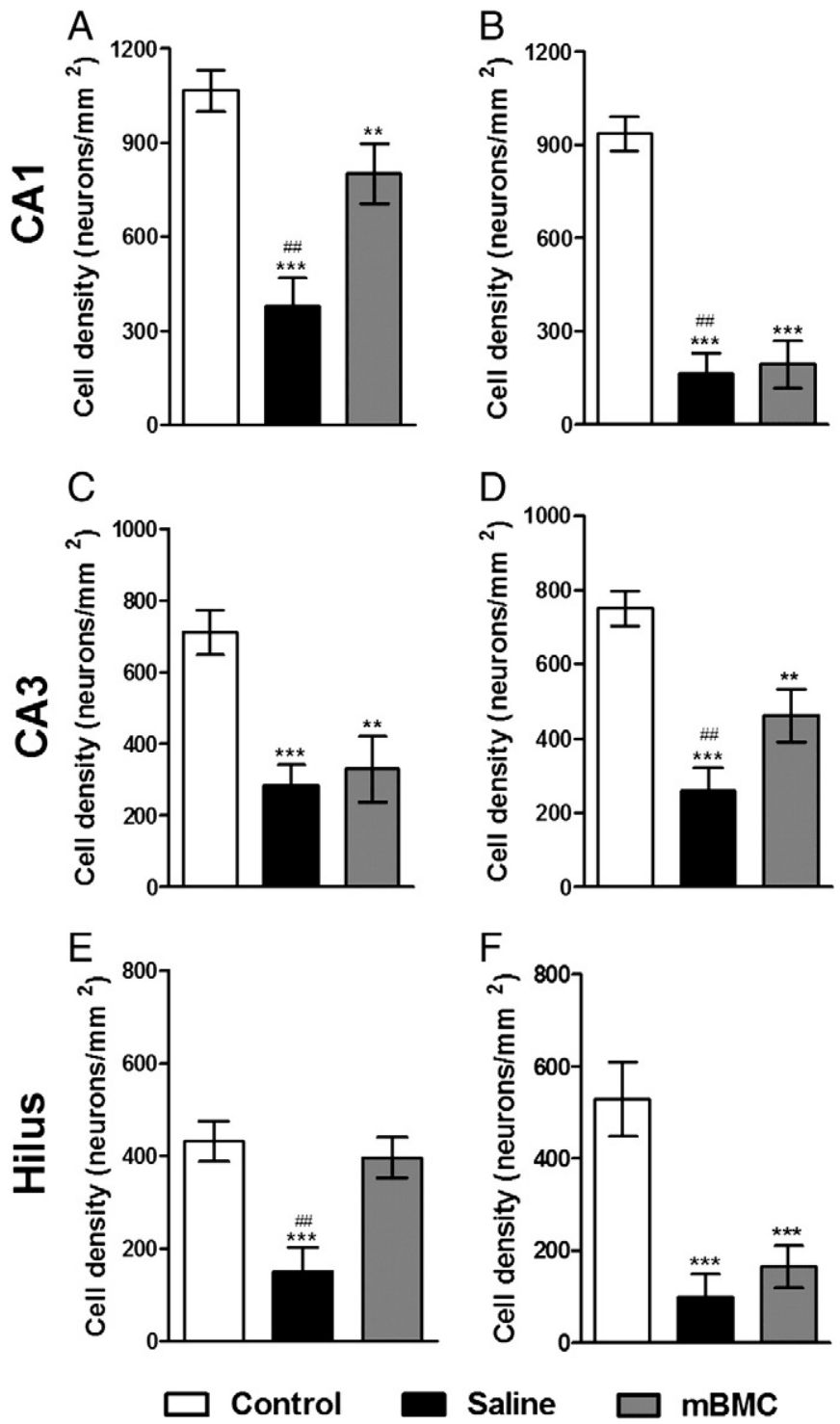

Fig. 5. Quantification of neuronal damage in the hippocampal formation. (A-F) Neuron counts from NeuN-stained brain sections in the area selected for quantification in CA1, CA3, and the hilus of the DG. Control (white), saline (black) and mBMC (gray) groups. Data are expressed as the mean \pm SEM, $n=5$ per group. Analyses of data by one-way ANOVA and Tukey's posttest indicated significant differences for all panels. Differences relative to the control group are indicated by ${ }^{*}(p<0.05)$ and between saline-epileptic vs. mBMC-epileptic rats by \# $(p<0.05)$.

the double-labeled cells had relatively large somata with visible dendrite-like processes and co-localized with NeuN in the CA3/CA4 area (Fig. 7E) and in the DG (Fig. 7F). DCX ${ }^{+}$cells were rarely found in brain sections of saline-epileptic rats at this time point (Fig. 7G); however, the numbers of $\mathrm{DCX}^{+}$cells were increased in the mBMC group (Fig. $7 \mathrm{H}, p<0.01$ ).

\section{Presence of bone marrow-derived $\mathrm{GFP}^{+}$cells in the epileptic brain}

The presence of transplanted $\mathrm{GFP}^{+}$cells in epileptic and controls rats was investigated. We found donor cells in the spleens of transplanted animals, indicating that the transplant was successful (data not shown). Rare $\mathrm{GFP}^{+}$cells were also found in the hippocampi of mBMCepileptic rats. Most the double-labeled cells appeared in pairs or in clusters (Figs. 8A and B) in different areas of the hippocampus three days 
Group A
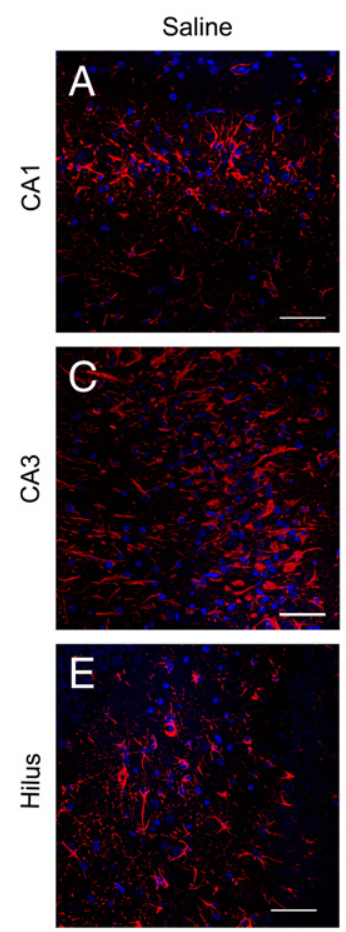

M

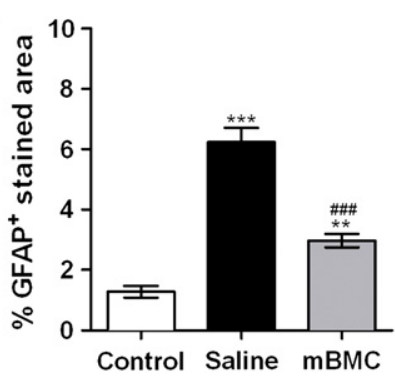

mBMC
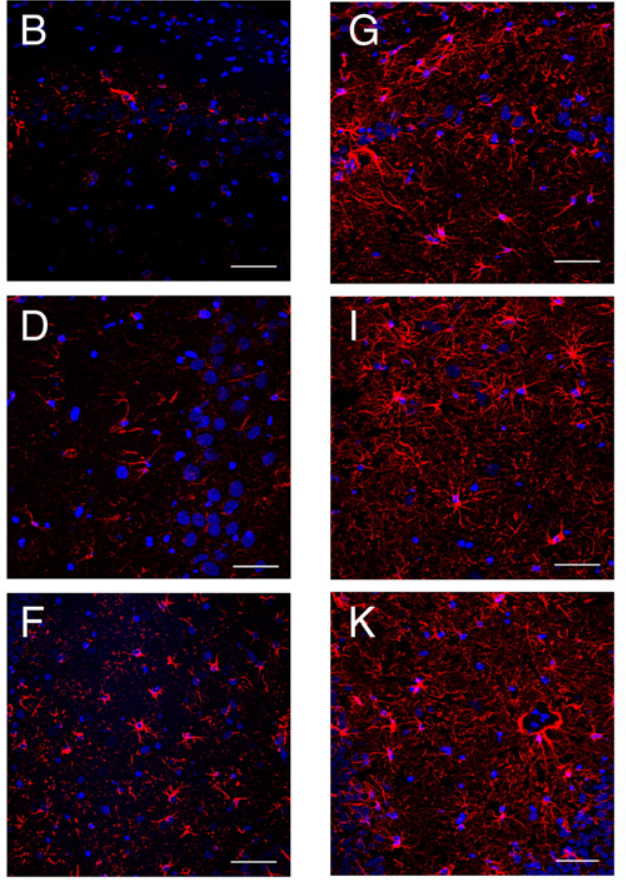

Saline
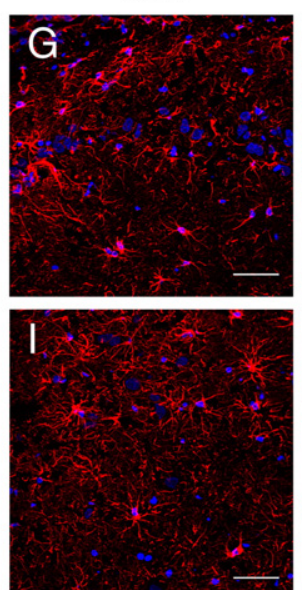

Group B
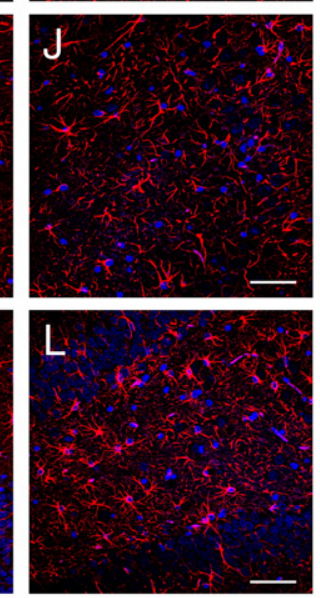

$\mathrm{N}$

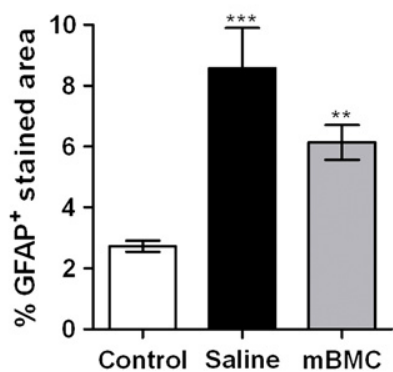

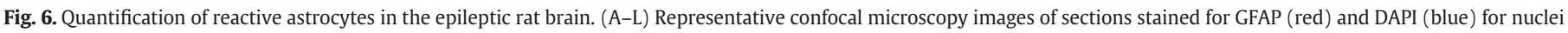

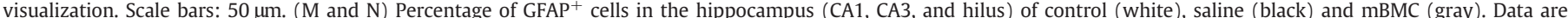

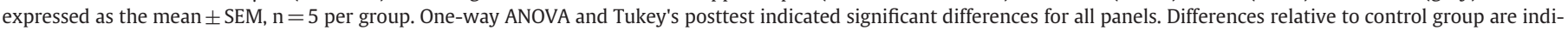
cated by ${ }^{*}(p<0.05)$ and between saline-epileptic vs. mBMC-epileptic rats by \# $(p<0.05)$.

after transplantation. However, none of these $\mathrm{GFP}^{+}$cells expressed neuronal or glial cell markers. To confirm the presence of mouse BMCs in the brain, we investigated GFP expression by quantitative real-time PCR 45 and 60 days after transplantation in groups $A$ and $B$, respectively. In the mBMC transplanted group, the GFP mRNA level was significantly higher, suggesting the presence of mouse BMCs in the brain (Fig. 8C).

\section{Expression of cytokines}

To investigate the mechanisms by which BMC therapy resulted in a reduction of seizures, we tested whether BMC transplantation modulates the transcription of TNF- $\alpha, I L-1 \beta, I L-6$, and IL-10. In group A, $T N F-\alpha, I L-1 \beta$ and IL-6 mRNA levels in epileptic rats were strikingly elevated compared to those of normal controls. After 3 and 45 days of transplantation, the expression of TNF- $\alpha$ mRNA was 3-fold greater than control levels in the epileptic group (Fig. 9A, $p<0.001$ ). IL-1 $\beta$ mRNA levels were increased in the brains of epileptic rats (Fig. 9B, $p<0.05$ and $p<0.001,3$ and 45 days, respectively). IL-6 mRNA expression was increased in epileptic brains in both time points analyzed (Fig. 9C, $p<0.01$ ). However, no differences in TNF- $\alpha, I L-1 \beta$ mRNA and IL-6 mRNA expression were found between mBMC-epileptic and control rats (Figs. 9A, B and C, $p>0.05$ ). In contrast to the pro- inflammatory cytokines, the mRNA levels of the anti-inflammatory cytokine $I L-10$ gene increased in $\mathrm{mBMC}$-treated epileptic rats in both time points analyzed (Fig. 9D, $p<0.001$ and $p<0.05,3$ and 45 days after mBMC, respectively). In group B, TNF- $\alpha, I L-1 \beta$ and IL- 6 mRNA was not significantly increased by mBMC transplantation (Figs. 9E, F and G). However, IL-10 mRNA was increased 2.0-fold in the mBMC-treated epileptic rats (Fig. $9 \mathrm{H}, p<0.01 \mathrm{mBMC}$ vs. control, and $p<0.05$ mBMC vs. epileptic-saline).

Three days after transplantation, serum levels of TNF- $\alpha$ and IL-1 $\beta$ were increased in the saline-epileptic rats (Figs. 9I and J, $p<0.05$ and $p<0.01$, respectively). In contrast, the levels of TNF- $\alpha$ and IL- $1 \beta$ were normal in rats transplanted with mBMC levels (Figs. 9I and J). The levels of IL-10 increased 1.6-fold in epileptic rats and 2.5-fold in mBMC-treated rats when compared to normal controls (Fig. 9K, $p<0.05$ control vs. epileptic, $p<0.001$ control vs. mBMC). IL-6 was not detected in the sera of any group (data not shown).

\section{Discussion}

Epilepsy is a debilitating neurological disorder characterized by recurrent seizures triggered by excessive neuronal excitability. In our study, BMCs were transplanted in epileptic rats either 22 days 


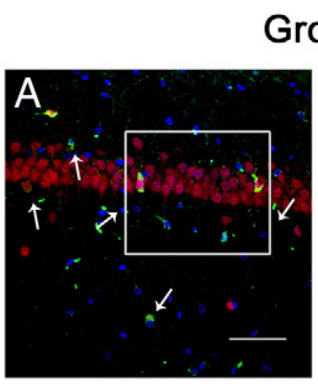

Group A
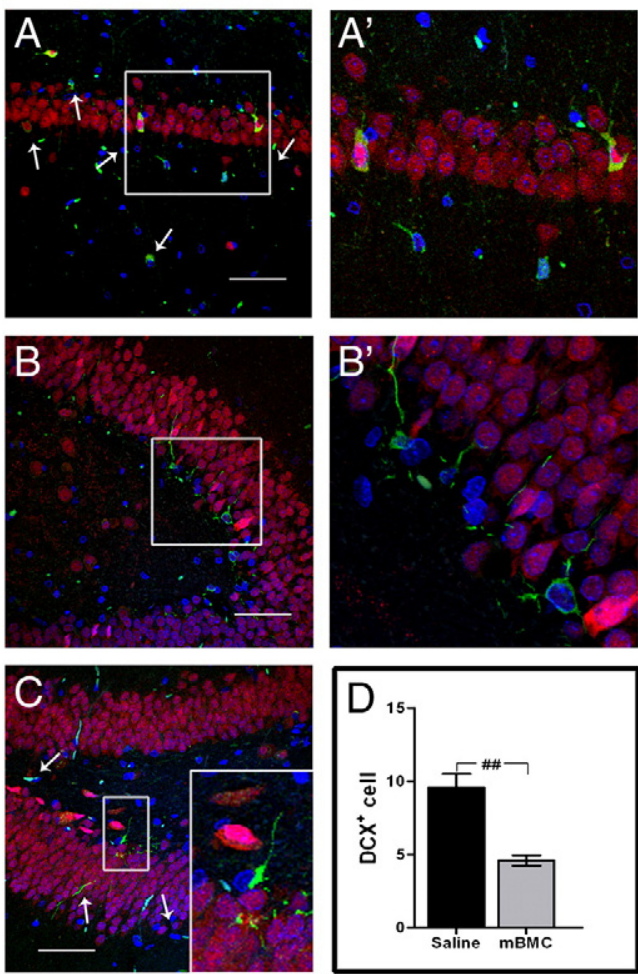
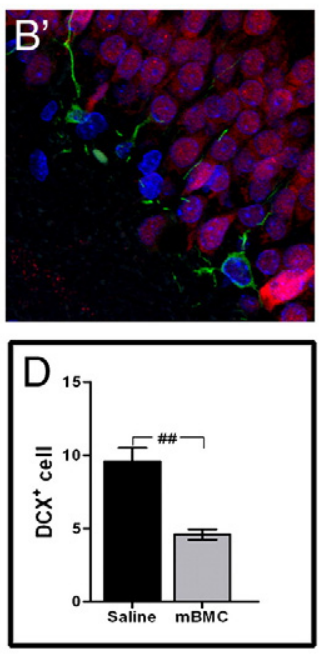
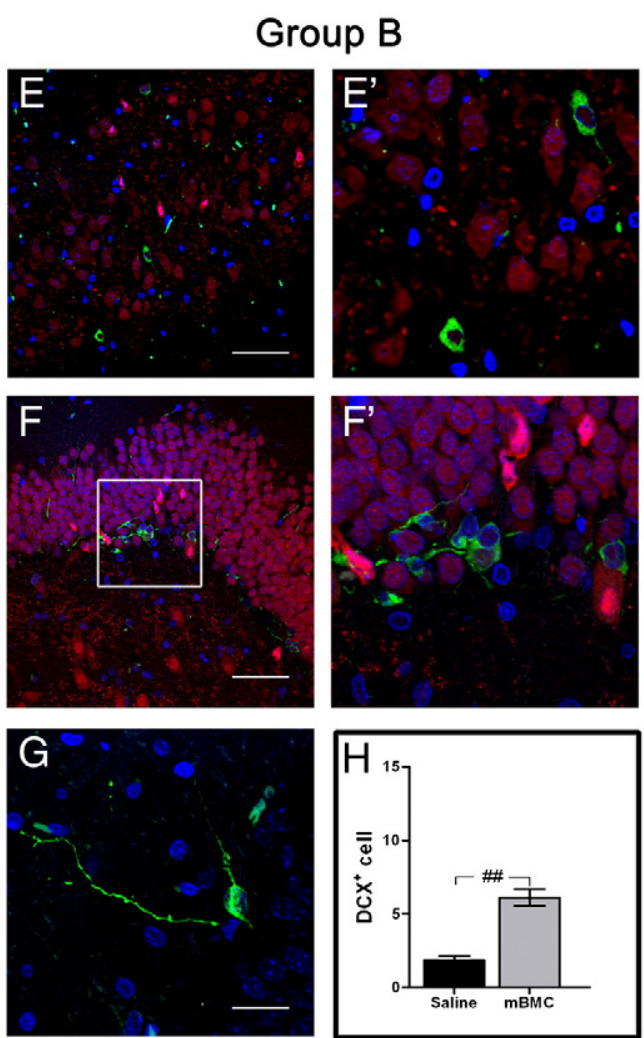

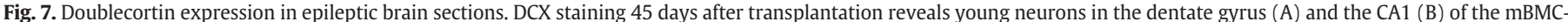

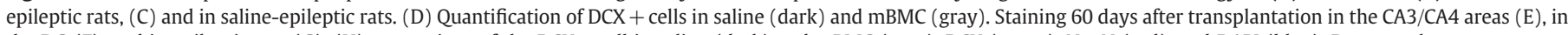

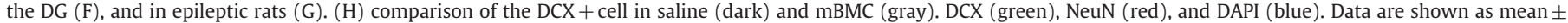
S.E.M., $\mathrm{n}=5$ per group, statistically significant differences indicated by $(\# \#, p<0.001)$ as determined by Mann-Whitney tests. Scale bar: $50 \mu \mathrm{m}$.

(group A) or 10 months after SE (group B). The data clearly show that, irrespective of the donor (syngeneic or xenogeneic), BMC-treated rats had a marked reduction in the frequency and duration of seizures compared with saline-treated epileptic rats. This reduction correlated with the downregulation of pro-inflammatory cytokine mRNA expression and upregulation of the anti-inflammatory cytokine IL-10 in the brain.

Several studies demonstrated that adult rats with SE have a number of morphologic changes, such as extensive neuronal loss in various temporal or extratemporal structures (for review, see Cavalheiro et al., 2006). Correlating with the decrease in SRS, we observed that the striking neuronal loss in CA1, CA3, and hilus of saline-treated epileptic rats did not occur in epileptic rats treated with BMC 22 days after SE. In fact, these animals showed a substantial preservation of the hippocampal neurons and maintenance of a functional neural network. In a previous study, we showed that BMC transplantation 22 days after SE ameliorated learning and spatial memory impairments in chronic epilepsy (Venturin et al., 2011).

Preservation of hippocampal neuron populations by the BMC therapy did not occur in rats transplanted after a longer period of SRS (10 months after SE, group B), since, by the time of transplantation, there was already an extensive established neuronal loss compared to normal controls. However, BMC-epileptic rats had an increase in the number of neurons when compared to saline-epileptic rats, and many of those expressed DCX, a marker of immature neurons. This result suggests an induction of endogenous neurogenesis by BMC therapy. We did not find any differences between non-epileptic controls and saline-epileptic rats regarding the number of $\mathrm{DCX}^{+}$cells in the hippocampus. In contrast, we found increased numbers of $\mathrm{DCX}^{+}$ cells in the hippocampus of both BMC-epileptic and saline-epileptic rats in the initial period of SRS (22 days after SE, group A). Salineepileptic rats had increased cell proliferation compared to BMCepileptic rats at this time point; therefore, the result may be explained by the increased frequency of seizures in the saline-epileptic group. It has been previously shown that seizures induce the proliferation, migration, and differentiation of neuronal progenitors in the hippocampus (Ming and Song, 2005). Furthermore, it was demonstrated that transplanted bone marrow cells pre-labeled with BrdU or retrovirus co-localize with mature neuronal markers, such as MAP-2 and NeuN, in ischemic injured brains (Crain et al., 2005; Hess et al., 2002; Kawada et al., 2006). We did not find donor cells in the brain expressing DCX, suggesting that transplanted bone marrow cells have a paracrine effect in our model of epilepsy.

Pathological factors induce immediate morphological and functional changes in the cells, a compensatory response to changes in the extracellular environment. For example, reactive astrocytes become hypertrophic, with swollen cell bodies and processes. Longterm morphological changes in astrocytes may induce the proliferation (i.e., astrogliosis) and migration of these cells to nearby damaged neurons (Janeczko, 1994). Like neuronal damage, hippocampal glial activation is a common feature observed in experimental SE and in patients with mesial TLE (Aronica et al., 2000; Eid et al., 2008). Astrocytes can also synthesize and release proinflammatory cytokines (Vezzani et al., 2008). In this study, the reactive gliosis in mBMCtreated epileptic rat was less intense than that observed in salineepileptic rats, where glial cells seem to surround neurons in damaged areas. 

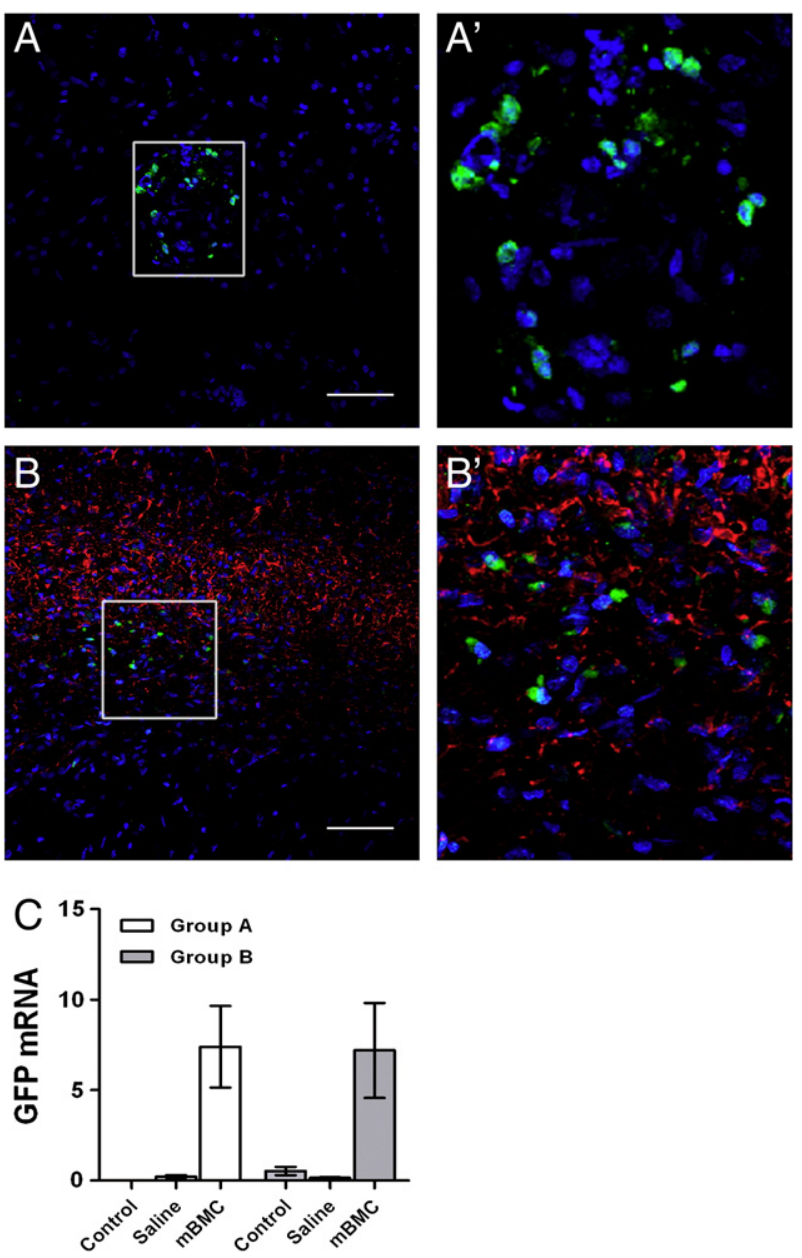

Fig. 8. Migration of transplanted $\mathrm{GFP}^{+}$cells to brains of mBMC-treated epileptic rats Brain sections from mBMC-epileptic rat stained with anti-GFP antibody (green), and counterstained with DAPI (blue) for nuclear visualization (A and B). (B) Sections were co-stained with anti-GFAP antibody (red). ( $A^{\prime}$ and $B^{\prime}$ ) Selected regions of $A$ and $B$ at higher magnification. Scale bars: $50 \mu \mathrm{m}$. (C) GFP mRNA levels in the brains of control and epileptic rats were normalized to GAPDH mRNA, demonstrating the presence of transplanted GFP expressing cells in the mBMC-epileptic brain ( $\mathrm{n}=4$ per group). **, $p<0.01$ compared to control and saline-epileptic groups, analysis of data by twoway ANOVA and Bonferroni posttest.

The reduction of SRS in BMC-epileptic rats may be related to the low levels of inflammatory cytokines detected in the brain and in the serum of animals treated with mBMC. Cytokines mediate cell communication and are released for autocrine and paracrine signaling (Vilcek, 1998). Excessive or sustained production of pro-inflammatory cytokines can contribute to neuronal hyperactivity and neurodegeneration in acute and chronic epilepsy (reviewed by Vezzani et al., 2011).

Several reports have reported increased production and secretion of pro-inflammatory cytokines (e.g., TNF- $\alpha$, IL-1 $1 \beta$, and IL-6) in the hippocampus after tonic-clonic seizures, which affect seizure severity and recurrence (see review by Li et al., 2011). For example, high levels of the pro-inflammatory cytokine TNF- $\alpha$ can cause severe damage via its action on p55 receptors by regulating the cellular trafficking of amino-3-hydroxy-5-methylisoxazole-4-propionic acid (AMPA) receptors and amplifying the glutamate responses from astrocytes (Bezzi et al., 2001). IL-1 $\beta$ induces the synthesis of IL-6 and TNF- $\alpha$ in astrocytes and microglia (Schobitz et al., 1994), and mice overexpressing IL- 6 and TNF- $\alpha$ in glia develop both seizures and neurodegeneration (Akassoglou et al., 1997; Campbell et al.,
1993). This cytokine can increase neuronal excitability by markedly inhibiting astrocytic glutamate uptake (Ye and Sontheimer, 1996), lowering gamma-aminobutyric acid (GABA) levels in the hippocampus, enhancing NMDA receptor function and $\mathrm{Ca}^{2+}$ influx, and inhibiting $\mathrm{K}^{+}$efflux (see by Rijkers et al., 2009).

Here, we have concentrated our analysis on classical pro- (TNF- $\alpha$, IL$1 \beta$, and IL-6) and anti-inflammatory cytokines (IL-10). We observed a marked reduction in the expression of the pro-inflammatory cytokines in the epileptic brains of rats treated with mBMC compared to salinetreated epileptic rats. We also demonstrated that BMC increased the expression of IL-10 transcripts in the brain and protein in the serum. BMC or bone marrow-derived mesenchymal stem cells have been shown to have immunomodulatory effects through their effect on IL-10 expression in a rat model of cerebral infarction (Brenneman et al., 2010; Liu et al., 2009) and by providing a favorable microenvironment for neurogenesis after ischemic stroke (Morita et al., 2007). In addition to cytokine modulation, the combination of other mechanisms, such as increased neuroprotection and neurogenesis promoted by neurotrophic and growth factors, could be responsible for the observed effects. In this regard, it has been shown that in the hippocampus of epileptic rats, glial-cell-derived neurotrophic factor (GDNF) attenuates epileptogenesis (Kanter-Schlifke et al., 2007), while brain-derived neurotrophic factor (BDNF) increases neurogenesis, reduces neuronal loss, and decreases the occurrence of spontaneous seizures (Bovolenta et al., 2010). Increased expression of BDNF and neural growth factor (NGF) was reported in a stroke model after mesenchymal stem cell transplantation (reviewed by Dharmasaroja, 2008). It is possible that BMC treatment modulated neurotrophin expression, a possibility we intend to explore in future studies.

Our BMC treatment consisted of different cell types present in the mononuclear cell fraction, including monocytes and mesenchymal and endothelial precursors, which may have different and additive therapeutic potentials. Recently, we demonstrated that despite a significant functional recovery of rats transplanted with BMC immediately after SE (Costa-Ferro et al., 2010), or 22 days after SE (Venturin et al., 2011), only a few transplanted cells were found in the brain. This result was corroborated in the current study; only a small number of donor cells were found in the epileptic brain, confirming the low rate of migration of BMC to the brain.

In conclusion, this study shows that BMC transplantation in epileptic rats has potent therapeutic actions. Most importantly, the frequency and duration of seizures were reduced regardless of whether the transplant was performed in the initial phase or after a protracted period of SRS. BMC preserved neurons, reduced astrocyte activation, and induced the proliferation of new neurons in the DG. Activation and proliferation of progenitor cells was also found in other hippocampal subregions, including CA1 and CA3, possibly due to a modulation of the inflammatory response following treatment with BMC. Our results indicate that BMC, which are easily obtainable for autologous application, may be a safe and effective therapy for treating chronic epilepsy.

\section{Disclosure}

The authors declare no conflicts of interest.

\section{Acknowledgments}

This work was supported by the Brazilian National Research Council (CNPq), Instituto de Pesquisa Biomédica (IPB) and Instituto do Cérebro (InsCer) da Pontifícia Universidade Católica do Rio Grande do Sul (PUCRS), Centro de Biotecnologia e Terapia Celular do Hospital São Rafael, Salvador-BA (CBTC-BA), FAPESB and FINEP. The authors would like to thank Juliana Vasconcelos for assistance with ELISA experiments. 


\section{Group A}
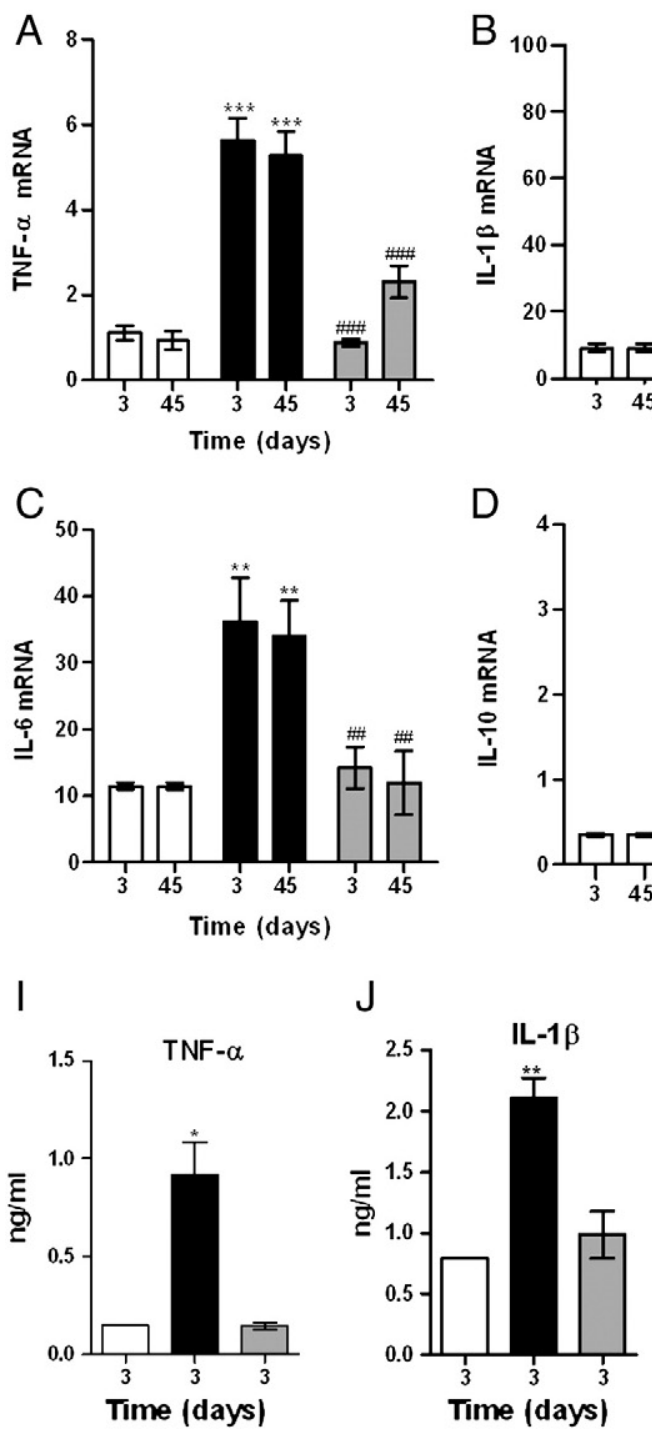
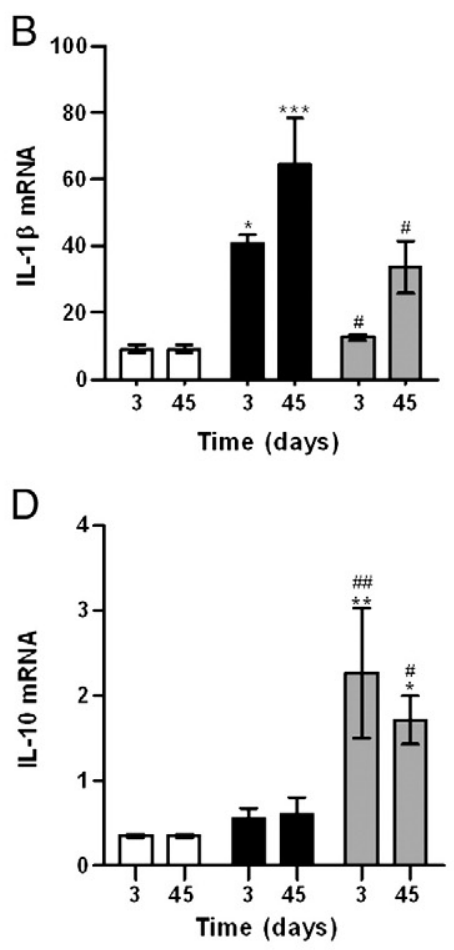

$J$

$\mathrm{K}$
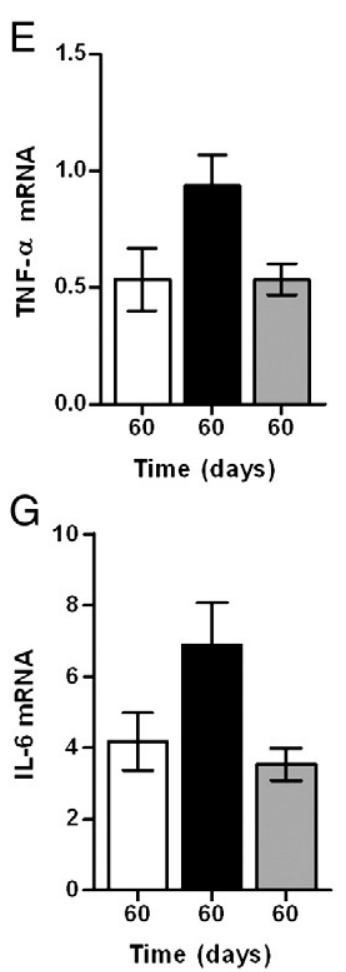

Group B

$\mathrm{F}$

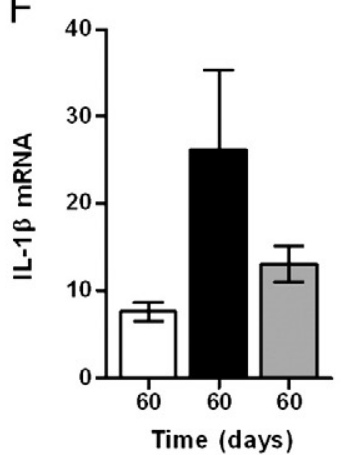

$\mathrm{H}$

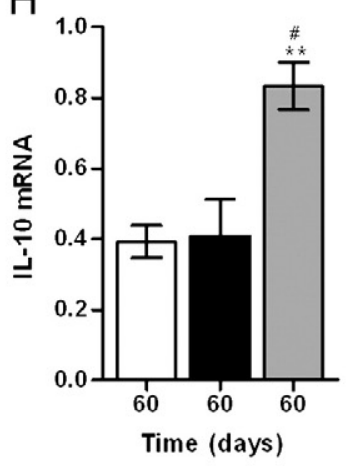

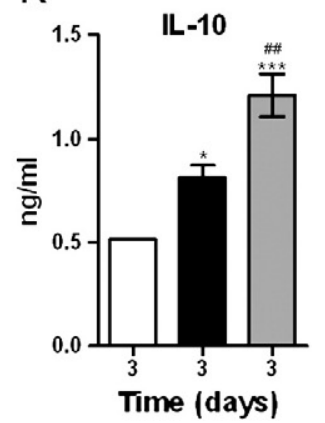

$\square$

Control

Saline

mBMC

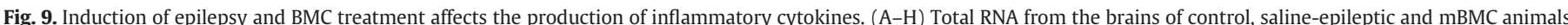

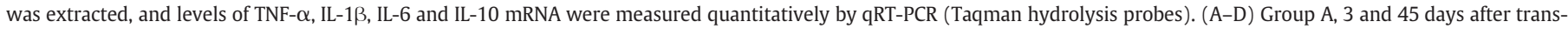

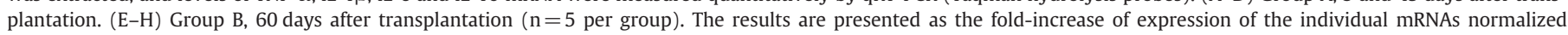

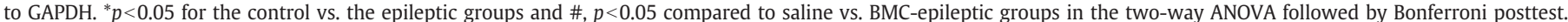

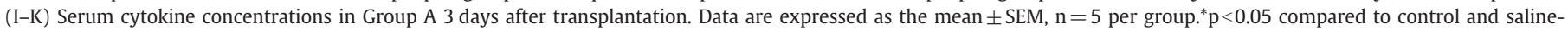
epileptic groups and \#, $p<0.05$ compared to epileptic and BMC-epileptic groups in the one-way ANOVA and followed by Newman-Keuls multiple comparison test.

\section{References}

Abercrombie, M., 1946. The density of neurones in the human hippocampus. Anat. Rec. 94, 239-247.

Akassoglou, K., Probert, L., Kontogeorgos, G., Kollias, G., 1997. Astrocyte-specific but not neuron-specific transmembrane TNF triggers inflammation and degeneration in the central nervous system of transgenic mice. J. Immunol. 58, 438-445.

Aronica, E., van Vliet, E.A., Mayboroda, O.A., Troost, D., da Silva, F.H., Goiter, J.A., 2000. Upregulation of metabotropic glutamate receptor subtype mGluR3 and mGluR5 in reactive astrocytes in a rat model of mesial temporal lobe epilepsy. EJN 12, 2333-2344.

Baker, A.H., Sica, V., Work, L.M., Williams-Ignarro, S., de Nigris, F., Lerman, L.O., Casamassimi, A., Lanza, A., Schiano, C., Rienzo, M., Ignarro, L.J., Napoli, C., 2007. Brain protection using autologous bone marrow cell, metalloproteinase inhibitors, and metabolic treatment in cerebral ischemia. Proc. Natl. Acad. Sci. U. S. A. 104, 3597-3602.

Bao, X., Wei, J., Feng, M., Lu, S., Li, G., Dou, W., Ma, W., Ma, S., Na, Y., Qin, C., Zhao, R.C. Wang, R., 2011. Transplantation of human bone marrow-derived mesenchymal stem cells promotes behavioral recovery and endogenous neurogenesis after cerebral ischemia in rats. Brain Res. 7, 103-113.

Bezzi, P., Domercq, M., Brambilla, L., Galli, R., Schols, D., De Clercq, E., Vescovi, A., Bagetta, G., Kollias, G., Meldolesi, J., Volterra, A., 2001. CXCR4-activated astrocyte glutamate release via TNFalpha: Amplification by microglia triggers neurotoxicity. Nat. Neurosci. 4, 702-710.
Bovolenta, R., Zucchini, S., Paradiso, B., Rodi, D., Merigo, F., Navarro Mora, G., Osculati, F., Berto, E., Marconi, P., Marzola, A., Fabene, P.F., Simonato, M., 2010. Hippocampal FGF-2 and BDNF overexpression attenuates epileptogenesis-associated neuroinflammation and reduces spontaneous recurrent seizures. J. Neuroinflammation 18, 7:81.

Brazelton, T.R., Rossi, F.M.V., Keshet, G.I., Blau, H.M., 2000. From marrow to brain: expression of neuronal phenotypes in adult mice. Science 290, 1775-1779.

Brenneman, M., Sharma, S., Harting, M., Strong, R., Cox Jr., C.S., Aronowski, J., Grotta, J.C., Savitz, S.I., 2010. Autologous bone marrow mononuclear cells enhance recovery after acute ischemic stroke in young and middle-aged rats. J. Cereb. Blood Flow Metab. 30, 140-149.

Campbell, I.L., Abraham, C.R., Masliah, E., Kemper, P., Inglis, J.D., Oldstone, M.B., Mucke, L. 1993. Neurologic disease induced in transgenic mice by cerebral overexpression of interleukin 6. Proc. Natl. Acad. Sci. U. S. A. 90, 10061-10065.

Cavalheiro, E.A., Naffah-Mazacoratti, M.G., Mello, L.E., Leite, J.P., 2006. The pilocarpine modelo of seizures. In: Pitkanen, A., Schwartzkroin, P.A., Moshé, S.L. (Eds.), Models of Seizures and Epilepisy. Elsevier, Amsterdam, pp. 433-448.

Chopp, M., Li, Y., 2002. Treatment of neural injury with marrow stromal cells. Lancet Neurol. 1, 92-100.

Clifford, D.B., Olney, J.W., Maniotis, A., Collins, R.C., Zorumski, C.F., 1987. The functional anatomy and pathology of lithium-pilocarpine and high-dose pilocarpine seizures. Neuroscience 23, 953-968.

Costa-Ferro, Z.S., Vitola, A.S., Pedroso, M.F., Cunha, F.B., Xavier, L.L., Machado, D.C., Soares, M.B., Ribeiro-dos-Santos, R., DaCosta, J.C., 2010. Prevention of seizures 
and reorganization of hippocampal functions by transplantation of bone marrow cells in the acute phase of experimental epilepsy. Seizure 19, 84-92.

Crain, B.J., Tran, S.D., Mezey, E., 2005. Transplanted human bone marrow cells generate new brain cells. J. Neurol. Sci. 233, 121-123.

de Vasconcelos dos Santos, A., da Costa Reis, J., Diaz, 2010. Therapeutic window for treatment of cortical ischemia with bone marrow-derived cells in rats. Brain Res. 1306, 149-158.

Dharmasaroja, P., 2008. Bone marrow-derived mesenchymal stem cells for the treatment of ischemic stroke. J. Clin. Neurosci. 1, 12-20.

Eglitis, M.A., Mezey, E., 1997. Hematopoietic cells differentiate into both microglia and macroglia in the brains of adult mice. Proc. Natl. Acad. Sci. 94, 4080-4085.

Eid, T., Williamson, A., Lee, T.S., Petroff, O.A., de Lanerolle, N.C., 2008. Glutamate and astrocytes-key players in human mesial temporal lobe epilepsy? Epilepsia 49, 42-52.

Engel Jr., J., 1996. Introduction to temporal lobe epilepsy. Epilepsy Res. 26, 141-150.

Engel Jr., J., 2001a. Mesial temporal lobe epilepsy: what have we learned? Neuroscientist 7, 340-352.

Engel Jr., J., 2001b. A proposed diagnostic scheme for people with epileptic seizures and with epilepsy: report of the ILAE Task Force on Classification and Terminology. Epilepsia 42, 796-803.

Franklin, K.B.J., Paxinos, G., 1997. The Mouse Brain in Stereotaxic Coordinates. Academic, San Diego.

Giraldi-Guimarães, A., Rezende-Lima, M., Bruno, F.P., Mendez-Otero, R., 2009. Treatment with bone marrow mononuclear cells induces functional recovery and decreases neurodegeneration after sensorimotor cortical ischemia in rats. Brain Res. $1266,108-120$.

Hess, D.C., Hill, W.D., Martin-Studdard, A., Carroll, J., Brailer, J., Carothers, J., 2002. Bone marrow as a source of endothelial cells and NeuN-expressing cells After stroke. Stroke 33, 1362-1368.

Hu, D.Z., Zhou, L.F., Zhu, J.H., 2004. Marrow stromal cells administrated intracisternally to rats after traumatic brain injury migrate into the brain and improve neurological function. Chin. Med. J. 117, 1576-1578.

Iihoshi, S., Honmou, O., Houkin, K., Hashi, K., Kocsis, J.D., 2004. A therapeutic window for intravenous administration of autologous bone marrow after cerebral ischemia in adult rats. Brain Res. 1007, 1-9.

Janeczko, K., 1994. The proliferative activity of astrocytes after immunoglobulin uptake in the injured mouse cerebral hemisphere. Folia Histochem. Cytobiol. 32, 239-241.

Kamiya, N., Ueda, M., Igarashi, H., Nishiyama, Y., Suda, S., Inaba, T., Katayama, Y., 2008 Intra-arterial transplantation of bone marrow mononuclear cells immediately after reperfusion decreases brain injury after focal ischemia in rats. Life Sci. 83, 433-437.

Kanter-Schlifke, I., Georgievska, B., Kirik, D., Kokaia, M., 2007. Seizure suppression by GDNF gene therapy in animal models of epilepsy. Mol. Ther. 15, 1106-1113.

Kawada, H., Takizawa, S., Takanashi, T., Morita, Y., Fujita, J., Fukuda, K., Takagi, S., Okano, H., Ando, K., Hotta, T., 2006. Administration of hematopoietic cytokines in the subacute phase after cerebral infarction is effective for functional recovery facilitating proliferation of intrinsic neural stem/progenitor cells and transition of bone marrow-derived neuronal cells. Circulation 113, 701-710.

Li, G., Bauer, S., Nowak, M., Norwood, B., Tackenberg, B., Rosenow, F., Knake, S., Oertel, W.H., Hamer, H.M., 2011. Cytokines and epilepsy. Seizure 20, 249-256.

Liu, N., Chen, R., Du, H., Wang, J., Zhang, Y., Wen, J., 2009. Expression of IL-10 and TNFalpha in rats with cerebral infarction after transplantation with mesenchymal stem cells. Cell. Mol. Immunol. 6, 207-213.
Mathern, G.W., Babb, T.L., Leite, J.P., Pretorius, K., Yeoman, K.M., Kuhlman, P.A., 1996. The pathogenic and progressive features of chronic human hippocampal epilepsy. Epilepsy Res. 26, 151-161.

Mello, L.E., Cavalheiro, E.A., Tan, A.M., Kupfer, W.R., Pretorius, J.K., Babb, T.L., Finch, D.M., 1993. Circuit mechanisms of seizures in the pilocarpine model of chronic epilepsy: cell loss and mossy fiber sprouting. Epilepsia 34, 985-995.

Ming, G.L., Song, H., 2005. Adult neurogenesis in the mammalian central nervous system. Annu. Rev. Neurosci. 28, 223-250.

Morita, Y.S., Takizawa, H., Kamiguchi, T., Uesugi, H., Kawada, Takagi, S., 2007. Administration of hematopoietic cytokines increases the expression of anti-inflammatory cytokine (IL-10) mRNA in the subacute phase after stroke. Neurosci. Res. 58, 356-360.

Parent, J.M., Yu, T.W., Leibowitz, R.T., Geschwind, D.H., Sloviter, R.S., Lowenstein, D.H., 1997. Dentate granule cell neurogenesis is increased by seizures and contributes to aberrant network reorganization in the adult rat hippocampus. J. Neurosci. 17, 3727-3738.

Racine, R.J., 1972. Modification of seizure activity by electrical stimulation. I: afterdischarge threshold. Electroencephalogr. Clin. Neurophysiol. 32, 269-279.

Rijkers, K., Majoie, H.J., Hoogland, G., Kenis, G., De Baets, M., Vles, J.S., 2009. The role of interleukin-1 in seizures and epilepsy: a critical review. Exp. Neurol. 216 (2), 258-271.

Schobitz, B., De Kloet, E.R., Holsboer, F., 1994. Gene expression and function of interleukin 1, interleukin 6 and tumor necrosis factor in the brain. Prog. Neurobiol. 44, 397-432.

Takahashi, M., Li, T.S., Suzuki, R., Kobayashi, T., Ito, H., Ikeda, Y., Matsuzaki, M., Hamano, K., 2006. Cytokines produced by bone marrow cells can contribute to functional improvement of the infarcted heart by protecting cardiomyocytes from ischemic injury. Am. J. Physiol. Heart Circ. Physiol. 291, 886-893.

Turski, L. Cavalheiro, E.A. Czuczwar, S.J., Turski, W.A., Kleinrok, Z, 1987. The seizures induced by pilocarpine: behavioral, electroencephalographic and neuropathological studies in rodents. Pol. J. Pharmacol. Pharm. 39, 545-555.

Venturin, G.T., Greggio, S., Marinowic, D.R., Zanirati, G., Cammarota, M., Machado, D.C., DaCosta, J.C., 2011. Bone marrow mononuclear cells reduce seizure frequency and improve cognitive outcome in chronic epileptic rats. Life Sci. 15, 229-234.

Vezzani, A., Granata, T., 2005. Brain inflammation in epilepsy: experimental and clinical evidence. Epilepsia 46, 1724-1743.

Vezzani, A., Bolosso, S., Ravizza, T., 2008. The role of cytokines in the pathophysiology of epilepsy. Brain Behav. Immun. 22, 797-803.

Vezzani, A., French, J., Bartfai, T., Baram, T.Z., 2011. The role of inflammation in epilepsy. Nat. Rev. Neurol. 7, 31-40.

Vilcek, J., 1998. The cytokines: an overview. In: Thomson, A. (Ed.), The Cytokine Handbook. Academic Press, San Diego, pp. 1-20.

Walker, P.A., Harting M.T, Shah, S.K., Day, M.C., El Khoury, R, Savitz, S.I., Baumgartner, J., Cox, C.S., 2010. Progenitor cell therapy for the treatment of central nervous system injury: a review of the state of current clinical trials. Stem Cells 20, 369578.

Wieser, H.G., 2004. Mesial temporal epilepsy with hippocampal sclerosis. ILAE Commission report. Epilepsia 45, 695-714.

Ye, C., Sontheimer, H., 1996. Cytokine modulation of glial glutamate uptake: a possible involvement of nitric oxide. Neuroreport 7, 2181-2185.

Zacharek, A., Shehadah, A., Chen, J., Cui, X., Roberts, C., Lu, M., Chopp, M., 2010. Comparison of bone marrow stromal cells derived from stroke and normal rats for stroke treatment. Stroke 41, 524-530. 